ISSN 1112-9867

http://www.jfas.info

\title{
PETROLEUM-HYDROCARBONS BIODEGRADATION BY Pseudomonas STRAINS ISOLATED FROM HYDROCARBON-CONTAMINATED SOIL
}

\author{
A. Benchouk ${ }^{*}$ and A. Chibani \\ Laboratory of Microbiology and Plant Science, Department of Biology, Faculty of Natural \\ and Life Sciences, University of Abdulhamid Ibn Badis, Mostaganem, Algeria.
}

Received: 18 Janaury 2017 / Accepted: 15 April 2017 / Published online: 01 May 2017

\begin{abstract}
Many indigenous microorganisms in water and soil are capable of degrading hydrocarbon contaminants. In this study, two bacterial strains were isolated from a contaminated soil of a refinery of Arzew (Oran). The isolated strains were identified as Pseudomonas aeruginosa (P3) and Pseudomonas fluoresens (P4). The capability of these isolates to degrade petroleum was performed by measuring the optical density, colony forming unit counts (CFU/ml) and concentration of total petroleum hydrocarbons (TPH). Degradation of Isomerate by these isolates was analyzed by gas chromatography with flame ionization detector (FID). Results indicated that the isolates can use petroleum as carbon source. Isolates P3 has the highest capability of hydrocarbons degradation ( $80.86 \%$ of biodegradation).
\end{abstract}

Keywords: Biodegradation, contaminated soil, Petroleum, Isomerate, Pseudomonas sp.

Author Correspondence, e-mail: abenchouk2011@gmail.com

doi: http://dx.doi.org/10.4314/jfas.v9i2.7 


\section{INTRODUCTION}

Pollution with petroleum hydrocarbons and their derivatives represent a serious problem for the environment and human health. Many petroleum hydrocarbons components are toxic, mutagenic and carcinogenic [1]. The refining, storage and distribution of crude oil and derivatives are important sources of soil and water pollution [2]. Petroleum hydrocarbons can be divided into four classes: The saturates, the aromatics, the asphaltenes, and the resins [3]. Soil is a key component of natural ecosystems because environmental sustainability depends largely on a sustainable soil ecosystem. When soil is polluted, the ecosystem is altered, and agricultural activities are affected. The soil remediation processes leading to the eventual removal of petroleum hydrocarbon and heavy metal, involve physical, chemical and biological techniques $[4 ; 5]$. However, physicochemical technologies are complex, expensive, environmentally unfriendly, and do not always resultin complete neutralization of pollutants. On the other hand bioremediation technology has been recognized to be a valuable alternative for the detoxification and disposal of toxic substance. This is because of their simplicity, cost-effectiveness, environmental friendliness, and conservation of soil texture and characteristics [4]. The process of bioremediation is an evolving method for the removal and degradation of many environmental pollutants including petroleum hydrocarbons. Biodegradation by microorganisms represents one of the primary mechanisms by which petroleum hydrocarbons pollutants can be removed from the environment [1]. Many environmental factors affect the rate of biodegradation process, which are soil moisture and $\mathrm{pH}$, availability of oxygenand nutrients, contaminant concentration [6]. The key role in bioremediation is played by microorganisms which are very diverse in nature and comprise bacteria, fungi, and yeast [5]. A number of bacterial species are known to degrade hydrocarbons including Pseudomonas aeruginosa, Pseudomons fluoresens, Mycobacterium spp., Haemophilus spp., Rhodococcus spp., Paenibacillus spp. [9]. The biodegradation of petroleum hydrocarbons is carried under aerobic and anaerobic conditions. There are two main strategies of bioremediation: bioaugmentation and biostimulation. In the first, the addition of oil-degrading microorganisms increases the rates of biodegradation, while in the second, the growth of indigenous hydrocarbon-degraders is stimulated by the addition of nutrient salts, surfactant or organic matter [6]. However, only very few Algerian works have 
been reported in the literature on the biodegradation of petroleum hydrocarbons with microorganisms isolated from contaminated soil [7; 8; 9].

The aim of the present work was to explore the hydrocarbon degradation capacity of microorganisms isolated from petroleum contaminated soil of a petroleum refinery. The identification of bacterial isolates was performed by biochemical analyses. In addition, the degradation capacity of petroleum by bacterial strains was performed by measuring the optical density, colony forming unit counts $(\mathrm{CFU} / \mathrm{ml})$ and concentration of total petroleum hydrocarbons (TPH). Degradation of Isomerate by isolates was characterized by GC/FID. In this study, we report bacterial isolates which are able to degrade efficiently a wide spectrum of hydrocarbons found in refined petroleum.

\section{EXPERIMENTAL METHOD}

\subsection{Soil samples}

Hydrocarbon contaminated soil samples were collected from the Arzew refinery in northern Algeria (Sonatrach, Algeria Petroleum Corporation). The refinery receives crude oil from the production site of Hassi Messaoud (located at $900 \mathrm{~km}$ in the south of Algiers). The refinery represents one of the largest oil industrial zones of Africa [10]. The samples were taken (in October 2014) using a clean spatula at a depth of $20 \mathrm{~cm}$. The soil is removed in sterile glass vials and was stored in the refrigerator at $4^{\circ} \mathrm{C}$. Petroleum was filtered with Filter unit $0.22 \mathrm{~m}$.

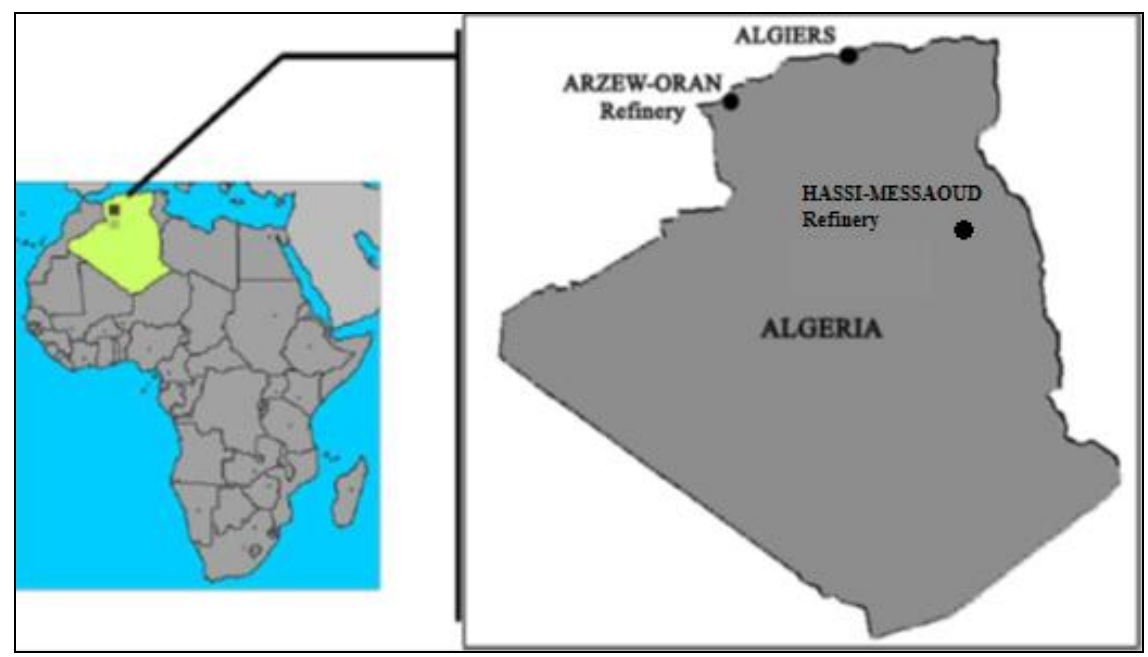

Fig.1. Map of Algeria, showing the localization of the petroleum refinery of ARZEW where the hydrocarbon contaminated soil samples was obtained [10]. 


\subsection{Enrichment and Isolation of aerobic hydrocarbons degrading bacteria}

Hydrocarbons-degrading bacteria were isolated on Bushnell-Haas medium (BH) [11], which contained per liter: $1.0 \mathrm{~g}$ of $\mathrm{KH} 2 \mathrm{PO} 4,1.0 \mathrm{~g}$ of $\mathrm{K} 2 \mathrm{HPO} 4,1.0 \mathrm{~g}$ of $\mathrm{NH} 4 \mathrm{NO} 3,0.2 \mathrm{~g}$ of MgSO4.7H2O, $0.05 \mathrm{~g}$ of $\mathrm{FeCl} 3$ and 0.02 gof $\mathrm{CaCl} 2 \cdot 2 \mathrm{H} 2 \mathrm{O}(\mathrm{pH} 7)$. For enrichment, $10 \mathrm{~g}$ contaminated soil was added to $100 \mathrm{ml}$ of $\mathrm{BH}$ medium containing 2\% (v/v) Petroleum [12]. Cultures were incubated in the dark at $30^{\circ} \mathrm{C}$ and $150 \mathrm{rpm}$. After one week, $2 \mathrm{ml}$ of enriched media was transferred into fresh $\mathrm{BH}$ medium and incubated at the same conditions as described above. After three consecutive transfers (interval of 1 week), 1001 of culture were plated on $\mathrm{BH}$ agar, which were covered with $100 \quad 1$ of Petroleum and incubated at $30^{\circ} \mathrm{C}[13$; 14]. Colonies were isolated, purified and stored at $4^{\circ} \mathrm{C}$ on nutrient agar. For long duration, the isolates are stored in glycerol $(30 \%)$ at $-50^{\circ} \mathrm{C}$.

Pure cultures of bacterial isolates were identified on the basis of their colonial morphology, cellular morphology and biochemical characteristics using API20 NE (bio Mérieux, Marcy-l'Etoile, France) according to the taxonomic scheme of Bergey's Manual of Determinative Bacteriology [15;16].

\subsection{Kinetic of HydrocarbonsDegrading Isolates}

The ability to degrade petroleum was performed as described by Koolivand et al., (2013) [17] with modifications. Erlenmeyer Flasks of $250 \mathrm{ml}$ containing $100 \mathrm{ml}$ of $\mathrm{BH}$ Liquid medium with $2 \mathrm{ml}(2 \%)$ of petroleum were prepared. The isolates were incubated overnight in $5 \mathrm{ml}$ Nutrient Broth at $30^{\circ} \mathrm{C}$. After incubation, the cultures were centrifuged at $6000 \mathrm{rpm}$ for $15 \mathrm{~min}$ and cells collected. These were washed three times with BH liquid medium and re-suspended in a small volume $(5 \mathrm{ml})$ of the same medium [18], until OD600 was equivalent to 0.91[19].

One $\mathrm{ml}$ of inoculum (0.91 OD600 equivalent) was transferred into the flasks and Non-inoculated flasks were prepared as controls [20].

The cultures were grown in the dark at $30^{\circ} \mathrm{C}$ for 12 days with constant shaking (160 rpm) [19]. The growth patterns were measured using the optical density at $600 \mathrm{~nm}$ [21] and the total viable counts $(\mathrm{CFU} / \mathrm{ml})[22]$ of the isolates at intervals of 2 days. 
2.4. Determination of used hydrocarbons degradation by concentration of total petroleum hydrocarbons

The direct measurement of the dissipation of hydrocarbons in the culture medium is a clear means to evaluate the biodegradation of hydrocarbons [2]. Every 4 days, samples were taken from cultures Flasks for residual of TPH values (Total Petroleum Hydrocarbons) [22; 23] the TPH was measured with Oil Content Analyzer (Infrared spectroscopy, HORIBA, OCMA-310) (Method of NF M07-203). The extraction of the hydrocarbons can be done by polychlorotrifluoroethylene (HORIBA S-316 Solvent).

\subsection{Isomerate degradation assay by GC/FID}

The ability of isolates to degrade Isomerate (Naphta Petroleum, Refinery of Arzew, SONATRACH) in $\mathrm{BH}$ at $30^{\circ} \mathrm{C}$ with agitation at $160 \mathrm{rpm}$ was examined. Erlenmeyer flasks containing $100 \mathrm{ml}$ of $\mathrm{BH}$, supplemented with $2 \%$ of Isomerate, were inoculated with strains to a final OD600 of 0.91, parallel Erlenmeyer flasks, which were not inoculated with strains, were set up as controls to monitor loss of the hydrocarbons due to volatilization. After 15 days of incubation, inoculated flasks and un-inoculated controls were extracted $[24 ; 25]$. The extracts were analyzed by Gas Chromatography (DANI Master GC Fast Gas Chromatograph System, DANI Instruments Sp. A., Milan), with CP-Sil PONA CB Column (50mm, 0.21mm, $0.5 \mu \mathrm{m}$ ) and Flame Ionization Detector (FID). All runs were carried out under the following conditions: initial temperature $40^{\circ} \mathrm{C}$ for $1 \mathrm{~min}$; temperature rate $10^{\circ} \mathrm{C} / \mathrm{min}$ and final temperature $150^{\circ} \mathrm{C}$ for $1 \mathrm{~min}$; injector (spilt/splitless mode) temperature $250^{\circ} \mathrm{C}$; FID temperature $300^{\circ} \mathrm{C}$. Carrier gas constant flow rate (helium) $40 \mathrm{ml} / \mathrm{min}$. 


\section{RESULTS}

\subsection{Isolation and identification of isolates}

Two strains (P3 and P4) were isolated and characterized to have petroleum degrading capabilities. The isolates were respectively identified as Pseudomonas sp. (P3 and P4).

\subsection{Determination of hydrocarbons degradation by turbidometry and bacterial counts:}

Growth rate of the two isolatesin $\mathrm{BH}$ broth medium supplemented with $2 \%$ petroleum was evident from the significant increase in cell density at $600 \mathrm{~nm}$ and alternate colony counting after 12 days of incubation (Fig 2). The increase in optical density indicates the ability of cultures strains to utilize and degradepetroleum as source of energy.More specifically, this was observed between day 4 and 8 after which the growth became limited.The cell-concentration increased from $1.3 \times 105$ and $1.32 \times 105 \mathrm{CFU} / \mathrm{ml}$ in $\mathrm{BH}$ with Petroleum to $2 \times 109 \mathrm{CFU} / \mathrm{ml}$ on day 4 and $1.5 \times 109 \mathrm{CFU} / \mathrm{ml}$ on day 6 , for the isolates P3 and P4 respectively (Fig 2).

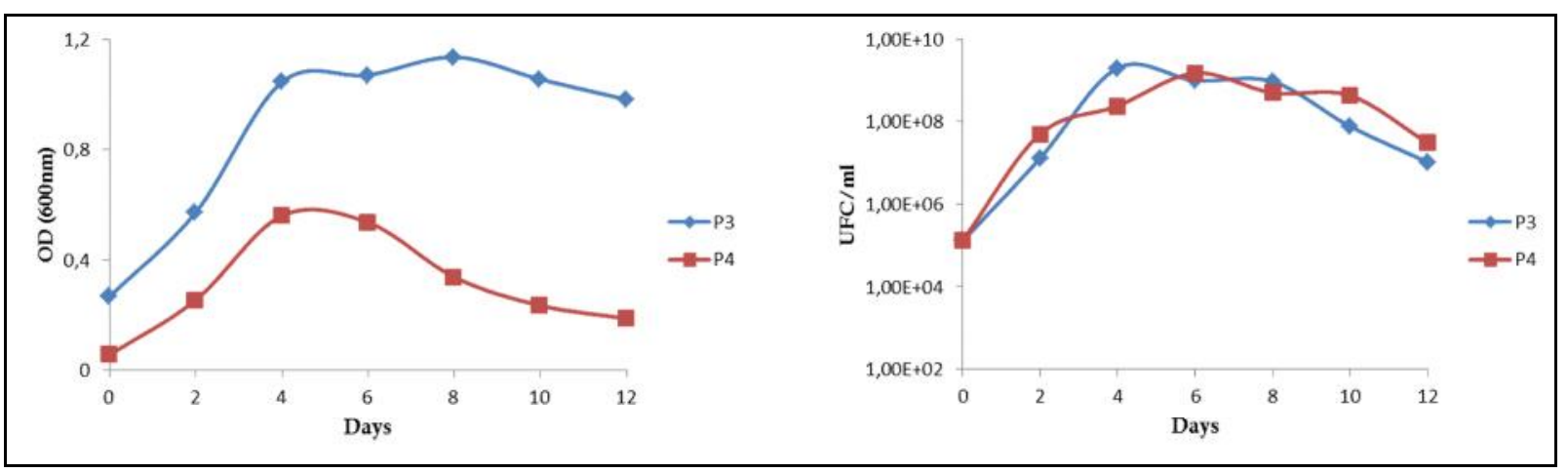

Fig.2. Growth rate of the isolates in BH broth medium supplemented with Petroleum (2\%) while 12 days of incubation at $30^{\circ} \mathrm{C}$.

\subsection{Determination of total petroleum hydrocarbons (TPH)}

The growth of bacteria in $\mathrm{BH}$ medium supplemented with $2 \%$ petroleum increased progressively with decrease in TPH throughout the monitoredperiod (12 days). The total amounts of TPH in the first day of incubation were 260 and $262 \mathrm{mg} / \mathrm{L}$ medium with petroleum for strains P3 and P4 respectively. The initial amount of TPH of the control was $282 \mathrm{mg} / \mathrm{L}$ (Fig 3). These curves indicate the degradation of petroleum by bacterial isolates 
because the amount of TPH decreased after 12 days of incubation to $49 \mathrm{mg} / \mathrm{L}$, and $169 \mathrm{mg} / \mathrm{L}$ in $\mathrm{BH}$ with petroleum for $\mathrm{P} 3$ and $\mathrm{P} 4$, respectively. At the beginning, the degradation rate was high but decreased with time due to the substrate exhaustion resulting from the use of the substrate by the isolates, as already hypothesized by Ichor et al., (2014) [26].

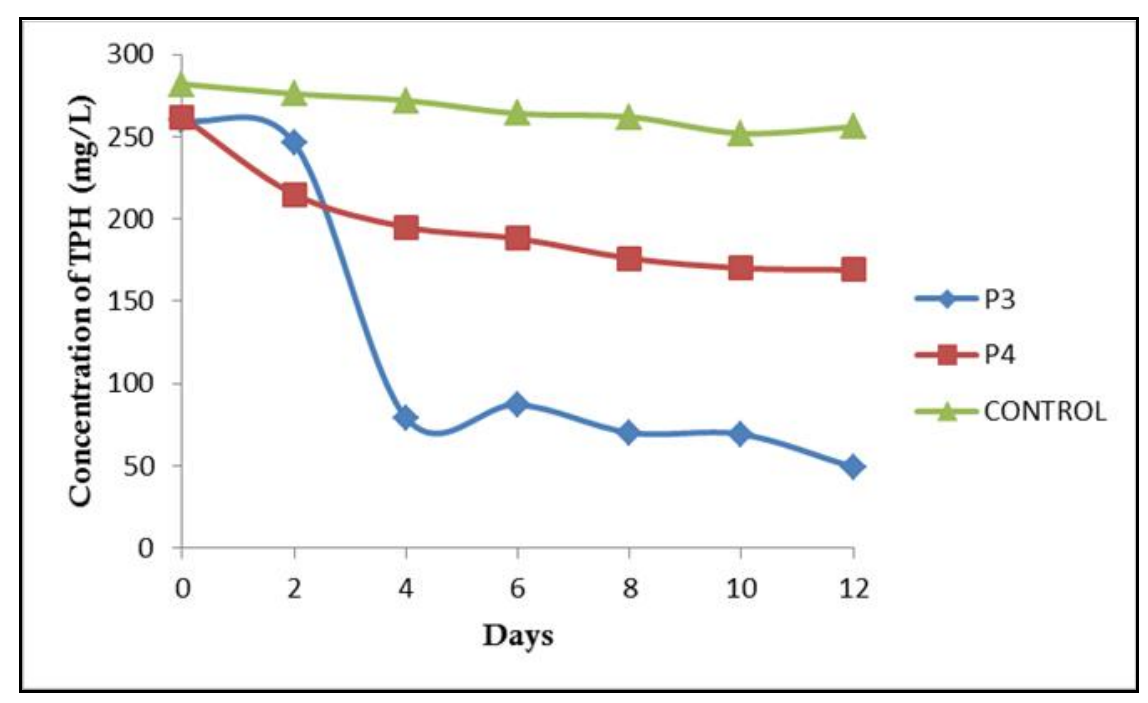

Fig.3. TPH degradation by isolated strains in $\mathrm{BH}$ broth medium supplemented with $2 \%$ of Petroleum while 12 days of incubation at $30^{\circ} \mathrm{C}$.

\subsection{Gas chromatographic analysis of Isomerate}

GC analysis of Isomerate inoculated with isolate P3 and P4 after 15 days of incubation (Fig 4). The results showed that the level of hydrocarbon has been significantly reduced with the appearance of degradation products ( $\mathrm{C} 1, \mathrm{C} 2, \mathrm{~N}-\mathrm{C} 4, \mathrm{~N}-\mathrm{C} 5$ and 2-2 dimethyl-butane) comparing with the control (Fig 4A). Fig 4B shows the disappearance of cyclopentane, Et-benzene and O-xylene were not visible after treatment with isolate P3. On the other hand, the treatment with isolate P4 (Fig 4C) favored the disappearance of I-C4 and hexane. According to results from GC-FID analysis, the percentage of Isomerate compounds's degraded was determined (Fig 5). 


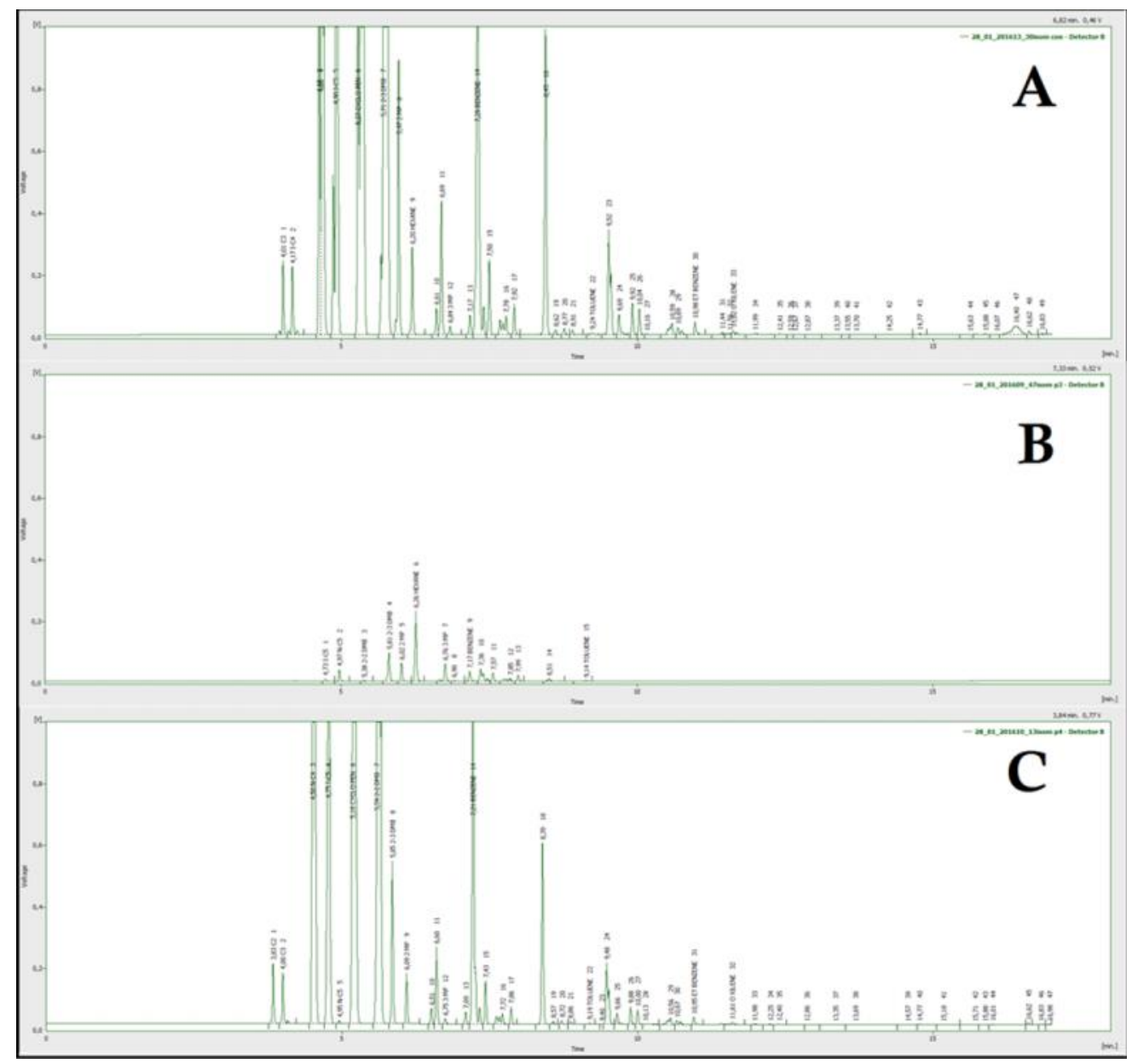

Fig.4. GC-FID analysis of Isomerate obtained without (A) and with treatment with microbial isolates: P3 (B) and P4 (C) for 15 days of incubation

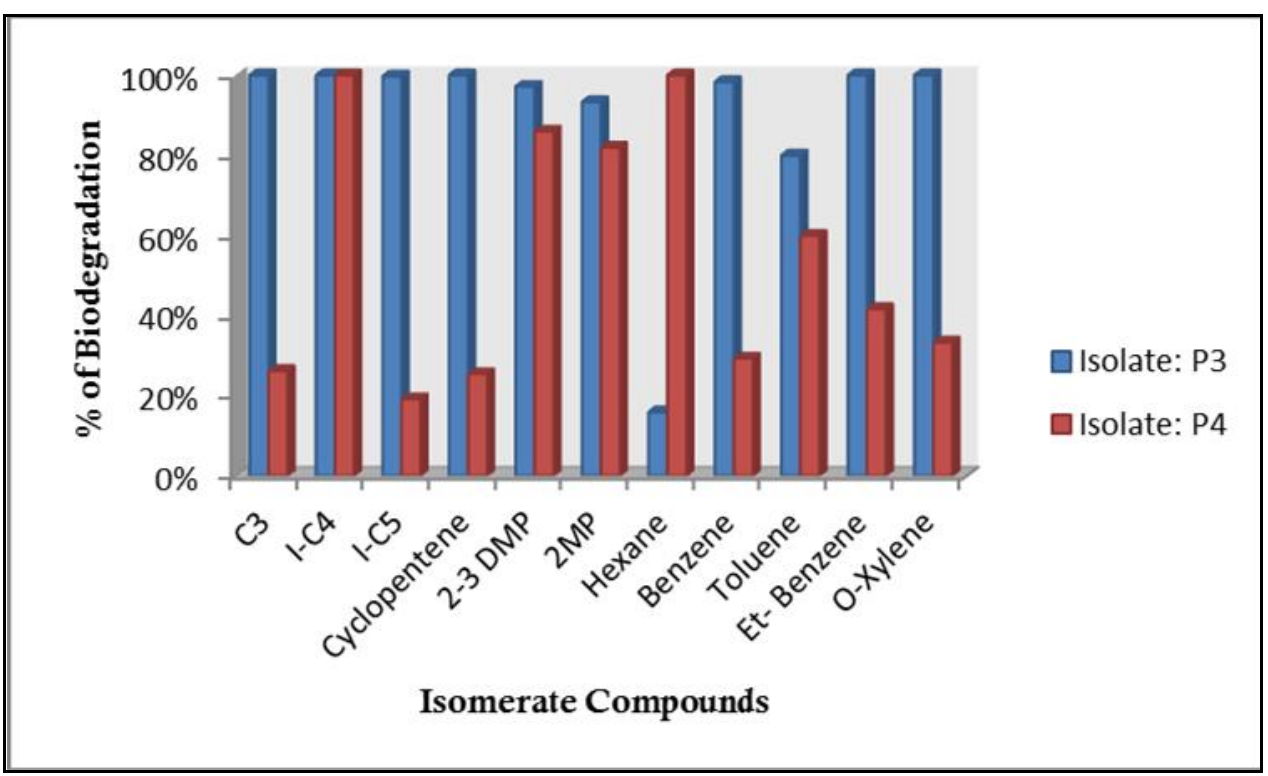

Fig.5. Percentage of Isomerate compounds's biodegradation by bacterial isolates (P3 and P4) after 15 days of incubation. 


\section{DISCUSSION}

Two bacterial strains used for this study were isolated by application of an enrichment technique from the contaminated soil of the refinery of Arzew, Northern Algeria. In the view of investigating their ability to retain their biodegradation potential of petroleum and Isomerate and employed those in bioremediation strategies of hydrocarbons contaminated sites. After morphological identification and number of biochemical tests, these isolates were included Pseudomonas sp. (P3 and P4).

Due to the presence of a complex enzymatic system the genus Pseudomonas exhibits a wide variety of metabolic and physiological properties [28]. They are also the most predominant group of microorganisms that degrade xenobiotic compounds [28]. In this study, the degradation of petroleum is observed by the significant increase in the population of isolates $\mathrm{P} 3$ and $\mathrm{P} 4$ in $\mathrm{BH}$ medium supplemented with $2 \%$ of petroleum as compared to the initial population. However, the higher growth rate was observed in P3 $(2 \times 109 \mathrm{UFC} / \mathrm{ml}$ with petroleum) compared to $\mathrm{P} 4(1.5 \times 109 \mathrm{UFC} / \mathrm{ml}$ with petroleum). These results agree with the observation of John et al., 2011 [29] that Pseudomonas aeruginosa exhibited greater ability to degrade hydrocarbons.

Biodegradation results demonstrated rapid utilization of the petroleum substance by the bacterial inoculums (Fig 3). From this result, it was clear that the P3 and P4 were able to degrade petroleum as sole source of carbon and energy since there was also loss in concentrations of total petroleum hydrocarbons (TPH). The best reduction in TPH (petroleum) was observed for isolates P3 as compared to control implying that the volatile components of the petroleum had evaporated. TPH loss was significant with time for isolates P4. Indeed, several Pseudomonas strains isolated from contaminated soil have been reported to grow on and/or degrade hydrocarbons or to remediate petroleum contaminated soils [27].

The growth of the isolates in BH supplemented with petroleum increased progressively with decrease in TPH (80.86\% for P3 and $33.98 \%$ for P4) throughout the 12 days period monitored. Ying et al., (2011) [30] and Jinlan, (2012) [31] reported a correlation between the significant decreases of TPH concentration to an increase in biomass bacterial indicating that the microorganisms were responsible for the degradation which corroborates our results. 
In the present study, isolate $\mathrm{P} 3$ proved to be better hydrocarbon degraders than isolate P4. P3 caused a complete degradation in fifteen days of incubation of five hydrocarbons were $\mathrm{C} 3$, I-C4, Cyclopentene, Et.benzene and O.xylene (Fig 4). Isolate P3 degraded more than $80 \%$ of the following hydrocarbons; I-C5, 2-3dimethylbutane, 2methylbutane, benzene and toluene (Fig 5). Benzene can be used as sole carbon and energy source for aerobic growth by many bacteria especially Pseudomonas species [32]. Whyte et al., (1997) [24] isolated three hydrocarbon-degrading bacteria from petroleum-contaminated Arctic soils and characterized two of the strains as Pseudomonas spp. The results obtained by Sutton et al., (2011) [33] indicate that the capability of Pseudomonas spp. to use hydrocarbons as the only sources of energy was explained by the production of lipidic biosurfactant that increase the ability of biodegradation. Isolate P4 has completely degraded I-C4 and hexane and more than $60 \%$ of 2-3 dimethylbutane, 2 methylbutane and toluene (Fig 5). Isolate P4 was identified as Pseudomonas fluoresens. This is a well-known degrader of benzene and toluene [34;35]. The relative differences in patterns of biodegradation of these substances can be explained by their molecular weights and chemical characteristics. Low molecular weight compound can be degraded relatively easily, while compounds of higher molecular weight require more time to be mineralized. Molecular structure also affects microbial degradation [36]. Highly branched alkanes and multi-ring cycloalkanes are slower to degrade than their straight-chain analogues [36].

\section{CONCLUSION}

In conclusion, in this study we have isolated and identified from contaminated soil two bacterial strains identified as Pseudomonas sp. with the ability to degrade hydrocarbons. The microbial degradative capabilities of hydrocarbons were monitored by different microbial methods including enumeration of hydrocarbon degraders, determination of total petroleum hydrocarbons (TPH) and gas chromatographic analysis of Isomerate. Petroleum and Isomerate were efficiently degraded by isolates P3 and P4. The results of this study showed that isolates P3 have the highest capability of hydrocarbons degradation compared to isolates P4. These isolates could be useful in hydrocarbon degradation and bioremediation of contaminated soil and have desirable oil bioremediation characteristics. 


\section{REFERENCES}

[1] Das N. and Chandran P. Microbial Degradation of Petroleum Hydrocarbon Contaminants: An Overview. Biotechnology Research International., 2011, 2011:13.

[2] Chioma B.C., Gideon C.O., and Blaise O.C. Monitoring of microbial hydrocarbon remediation in the soil.3 Biotech ., 2011, 1: 117-138 .

[3] Leahy J.G. and Colwell R.R. Microbial Degradation of Hydrocarbons in the Environment. Microbiological Reviews., 1990, 54(3): 305-315

[4] Agarry S.E. and Ogunleye O.O. Box-Behnken design application to study enhanced bioremediation of soil artificially contaminated with spent engine oil using biostimulation strategy. International Journal of Energy and Environmental Engineering., 2012, 3(31): 1-14 [5] Yadav B.K and Hassanizadeh M.S. An Overview of Biodegradation of LNAPLs in Coastal (Semi)-arid Environment. Water Air Soil Pollut., 2011, 220:225-239. DOI 10.1007/s11270-011-0749-1

[6] Kumar B.L and Gopal Sai D. V. R. Effective role of indigenous microorganisms for sustainable environment. 3 Biotech., 2015, 5:867-876. DOI 10.1007/s13205-015-0293-6[9] Haritash A.K. and Kaushik C.P. Biodegradation aspects of Polycyclic Aromatic Hydrocarbons (PAHs): A review. Journal of Hazardous Materials., 2009.169: 1-15

[7] Aouad L. and Abbouni B. Petroleum-Oil Biodegradation by Corynebacterium aquaticum and Pseudomonas aeruginosa Strains Isolated from the Industrial Rejection of the Refinery of ARZEW-Algeria. World Applied Sciences Journal., 2012, 18(8) : 1119-1123.

[8] Khemili T.S., Kebbouche G.S., Akmoussi T.S., Angar Y. and Gana M.L. Isolation of an extremely halophilic arhaeon Natrialba sp. C21 able to degrade aromatic compounds and to produce stable biosurfactant at high salinity. Extremophiles., 2015. 19: 1109-1120 .

[9] Guermouche M.A., Bensalah F. and Gray N.. Application of molecular methods as a biomarker in bioremediation studies, International Journal of Biotechnology Applications. , 2013,5(1): 147-154.

[10] Guermouche M., Bensalah A., Gury F.J. and Duran R. Isolation and characterization of different bacterial strains for bioremediation of n-alkanes and polycyclic aromatic hydrocarbons. Environ Sci Pollut Res., 2015, 22:15332-15346. DOI $10.1007 / \mathrm{s} 11356-015-4343-8$ 
[11] Atlas R. M. Handbook of Media for Environmental Microbiology (2 Ed.). Boca Raton: Taylor \& Francis Group., 2005, pp 664.

[12] Deziel E., Paquette G., Villemur R., Lepine F. and Bisaillon J. Biosurfactant Production by a Soil Pseudomonas Strain Growing on Polycyclic Aromatic Hydrocarbons. Applied and Environmental microbiology., 1996, 62(6): 1908.

[13] Daane L.L., Harjono I., Zylstra G.J., and Häggblom M.M. Isolation and Characterization of Polycyclic Aromatic Hydrocarbon-Degrading Bacteria Associated with the Rhizosphere of Salt Marsh Plants, Applied and Environmental Microbiology., 2001. 67(6): 2683-2691.

[14] Singh C. and Lin J. Isolation and characterization of diesel oil degrading indigenous microrganisms in Kwazulu-Natal, South Africa. African Journal of Biotechnology., 2008.7(12): 1927-1932.

[15] Brenner D.J., Krieg N.R. and Staley J.T. Bergey's Manual of Systematic Bacteriology (2 ed., Vol. II). Springer Dordrecht Heidelberg London New York., 2009 , pp 1106.

[16] De Vos.P, George M.G., Dorothy J., Noel R.K., Wolfgang L., Fred A.R., Karl-Heinz S. and William B.W. Bergey's Manual of Systematic Bacteriology (2 ed., Vol. III). Springer Dordrecht Heidelberg London New York., 2009. pp1422.

[17] Koolivand A., Kazem N., Ramin N., Simin N., Ahmad J.J., Massoud Y., and Kamyar Y. Degradation of petroleum hydrocarbons from bottom sludge of crude oil storage tanks using in-vessel composting followed by oxidation with hydrogen peroxide and Fenton. J Mater Cycles Waste Manag., 2013, 15: 321-327.

[18] Coral G. and Karagöz S. Isolation and characterization of phenanthrene-degrading bacteria from a petroleum refinery soil. Annals of Microbiology., 2005, 55(4): 255-259.

[19] Mueller J.G., Peter J.C., Beat O.B., and Hap Pritchard P. Isolation and Characterization of a Fluoranthene-Utilizing Strain of Pseudomonas paucimobilis. Applied and Environmental Microbiology., 1990, 56(4): 1079-1086.

[20] Boonchan S., Margaret L., Britz, and Grant A.S. Degradation and Mineralization of High-Molecular-Weight Polycyclic Aromatic Hydrocarbons by Defined Fungal-Bacterial Cocultures. Applied and Environmental Microbiology., 2000, 66 (3): 1007-1019.

[21] Heitkamp M.A., W. Franklin, and C.E. Cerniglia. Microbial Metabolism of Polycyclic Aromatic Hydrocarbons: Isolation and Characterization of a Pyrene-Degrading Bacterium, 
Applied and Environmental Microbiology., 1988,54 (10): 2549-2555.

[22] Balba M.T., Al-Awadhi N., and Al-Daher R. Bioremediation of oil-contaminated soil: microbiological methods for feasibility assessment and field evaluation. Journal of Methods Microbiological., 1998, 32: 155-164.

[23] Viñas M., Sabaté J., Espuny M.J. and Solanas A.M. Bacterial Community Dynamics and Polycyclic Aromatic Hydrocarbon Degradation during Bioremediation of Heavily Creosote-Contaminated Soil, Applied and Environmental Microbiology., 2005, 71 (11):7008-7018.

[24] Whyte L.G., Bourbonnière L., and Charles W. Greer. Biodegradation of Petroleum Hydrocarbons by Psychrotrophic Pseudomonas Strains Possessing Both Alkane (alk) and Naphthalene (nah) Catabolic Pathways, Applied and Environmental Microbiology., 1997. 63 (9): 3719-3723.

[25] Obire O. and Nwaubeta O. Biodegradation of Refined Petroleum Hydrocarbons in Soil. J. Appl. Sci. Environ. Mgt. , 2001, 5 (1): 43-46.

[26] Ichor T., Okerentugba P.O, and Okpokwasili G.C. Biodegradation of Total Petroleum Hydrocarbon by Aerobic Heterotrophic Bacteria Isolated from Crude Oil Contaminated Brackish Waters of Bodo Creek, J Bioremed Biodeg., 2014, 5 (5): 1-6.

[27] Das Kishore and Mukherjee Ashis K. Crude petroleum-oil biodegradation efficiency of Bacillus subtilis and Pseudomonas aeruginosa strains isolated from a petroleum-oil contaminated soil from North-East India, Bioresource Technology., 2007, 98: 1339-1345.

[28] Pacwa-Płociniczak Magdalena, Gra yna Anna Płaza, Anna Poliwoda and Zofia Piotrowska-Seget. Characterization of hydrocarbon-degrading and biosurfactant-producing Pseudomonas sp. P-1 strain as a potential tool for bioremediation of petroleum-contaminated soil. Environ Sci Pollut Res., 2014, 21:9385-9395. DOI 10.1007/s11356-014-2872-1

[29] John R.C., Itah A.Y., EssienJ.P. and Ikpe D.I. Fate of Nitrogen-Fixing Bacteria in Crude Oil Contaminated Wetland Ultisol, Bull Environ Contam Toxicol. , 2011, 87: 343-353.

[30] Ying Xu, Gao Dongmei, Liu Judong, and Wang Zhenyu. Plant-microbe Interactions to Improve Crude Oil Degradation. Energy Procedia., 2011, 5: 844-848.

[31] Jinlan Xu. 2012. Bioremediation of Crude Oil Contaminated Soil by Petroleum-Degrading Active Bacteria, Introduction to Enhanced Oil Recovery (EOR) 
Processes and Bioremediation of Oil-Contaminated Sites, Dr.Laura Romero-Zerón (Ed.) InTech,Availablefrom:http://www.intechopen.com/books/introduction-to-enhanced-oil-recove ry-eor-processes-and-bioremediationof-oil-contaminated-sites/bioremediation-of-oil-contamin ated-soil-by-highly-petroleum-degrading-bacteria

[32] Weelink Sander A. B., Miriam H. A. Van Eekert and Alfons J. M. Stams. 2010. Degradation of BTEX by anaerobic bacteria: physiology and application. Rev Environ Sci Biotechnol. 9: 359-385.

[33] Sutton Nora B., Tim J. Grotenhuis C., Alette A. Langenhoff M. and Huub H. Rijnaarts M.. Efforts to improve coupled in situ chemical oxidation with bioremediation: a review of optimization strategies, J Soils Sediments ., 2011, 11: 129-140

[34] Greene E.A., Kay J.G., Jaber K., Stehmeier L.G. and Voordouw G. Composition of soil microbial communities enriched on a mixture of aromatic hydrocarbons. Appl Environ Microbiol., 2000, 66:5282-5289

[35] Aburto Arturo and Peimbert Mariana. Degradation of a benzene-toluene mixture by hydrocarbon-adapted bacterial communities. Ann Microbiol., 2011, 61:553-562. DOI 10.1007/s13213-010-0173-6

[36] Swigert P. James, Carol Lee, Diana C.L. Wong and Paula Podhasky. Aquatic hazard and biodegradability of light and middle atmospheric distillate petroleum streams. Chemosphere., 2014, 108: 1-9

\section{How to cite this article:}

Benchouk A and Chibani A. Petroleum-hydrocarbons biodegradation by pseudomonas strains isolated from hydrocarbon-contaminated soil. J. Fundam. Appl. Sci., 2017, 9(2), 713-726. 